\title{
VALID INEQUALITIES AND CUTTING PLANES FOR SOME POLYTOPES
}

\author{
STEFAN M. STEFANOV
}

\begin{abstract}
In this paper we consider multidimensional knapsack polytope. Some important concepts and preliminaries are given at the beginning. Then we give a result connected with valid and dominating inequalities for this polytope, and a modular arithmetic approach for valid inequalities and cutting planes generation for the (one-dimensional) knapsack polytope.
\end{abstract}

Mathematics subject classification (1991): 90C27, 90C35.

Key words and phrases: Combinatorial optimization, integer programming, knapsack problem, valid inequalities, cutting planes.

\section{REFERENCES}

[1] E. BALAS, Facets of the knapsack polytope, Mathematical Programming, 8 (1975) 146-164.

[2] A. BRøNDSTED, An Introduction to Convex Polytopes, Springer-Verlag New York Inc., 1983.

[3] V. A. Yemelichev, V. I. Komlik, Method for Construction a Sequence of Plans for Solving Discrete Optimization Problems, Moscow, Nauka, 1981. (in Russian)

[4] V. A. Yemelichev, M. M. Kovalev, M. K. Kravtsov, Polytopes, Graphs and Optimization, Cambridge University Press, Cambridge, 1984.

[5] F. ForGO, Nonconvex Programming, Akademiai Kiado, Budapest, 1988.

[6] E. G. GolshteIn, D. B. YUdin, New Aspects of the Linear Programming, Moscow, Soviet Radio, 1966. (in Russian)

[7] R. E. GOMmoRY, Outline of an Algorithm for Integer Solutions to Linear Programs, Bulletin of the American Mathematical Society, 64 (1958) 275-278.

[8] _ Solving Linear Programming Problems in Integers, in: Combinatorial Analysis (R. Bellman and M. Hall, Jr., eds.), Proceedings of Simposia in Applied Mathematics X, American Mathematical Society, Providence, R.I., 1960, 211-215.

[9] - An Algorithm for Integer Solutions to Linear Programs, in: Recent Advances in Mathematical Programming (R. L. Graves and P. Wolfe, eds.), McGraw-Hill, New York, 1963, 269-302.

[10] P. L. Hammer, E. L. Johnson AND U. N. Peled, Facets of regular 0-1 polytopes, Mathematical Programming, 8 (1975) 179-206.

[11] G. L. Nemhauser And L. E. Trotter, JR., Properties of vertex packing and independence system polyhedra, Mathematical Programming, 6 (1974) 48-61.

[12] G. L. Nemhauser, L. A. Wolsey, Integer and Combinatorial Optimization, John Wiley \& Sons, 1988.

[13] M. W. PADBERG, On the facial structure of set packing polyhedra, Mathematical Programming, 5 (1973) 199-215.

[14] - A note on zero-one programming, Operations Research, 23 (1975) 833-837.

[15],$(1, k)$-configurations and facets for packing problems, Mathematical Programming, 18 (1980) 94-99.

[16] R. L. RARDIN, M. SUDIT, Paroids: a canonical format for combinatorial optimization, Discrete Applied Mathematics, 39 (1992) 37-56, North-Holland. 
[17] H. A. TAHA, Operations Research. An Introduction, Macmillan Publishing Co., Inc., New York; Collier Macmillan Publishers, London, 1982.

[18] R. Weismantel, On the 0/1 knapsack polytope, Mathematical Programming, 77 (1997) 49-68.

[19] L. A. WoLSEY, Faces for a linear inequality in $0-1$ variables, Mathematical Programming, 8 (1975) $165-178$. 